\title{
Nostalgia, Reflexivity, and the Narratives of Self: Reflections on Devine's "Removing
}

\author{
the Rough Edges?"
}

Consumption, Markets \& Culture

\begin{abstract}
Aliakbar Jafari (University of Strathclyde, Glasgow - UK) and Babak Taheri (Durham University - UK)
\end{abstract}

\begin{abstract}
This paper offers some theoretical insights on Devine's account of the Riverside Museum in Glasgow. It elaborates on three interrelated themes the authors have derived from Devine's report: 1) how historical representations arouse nostalgic sensations and sensibilities in museum visitors 2) the role of narratives in visitors' development of their nostalgic experiences 3) the importance of engagement to the creation of such nostalgic experiences. The paper contributes to the existing literature on nostalgia, experiential consumption, and the museum experience literature by establishing a relationship between nostalgia, reflexivity, and individuals' narratives of self in the conditions of (post/late/high) modernity.
\end{abstract}

Keywords: Nostalgia, Reflexivity, Modernity, Narrativity, Engagement, Museum

Kirsty Devine's account of the Riverside Museum (Scotland's Museum of Transport and Travel in Glasgow) is important for various reasons. The museum she depicts is an exemplar of successful development. It epitomizes a cultural enterprise that seeks to enhance its offerings primarily by incorporating the ideas and ideals of its key stakeholders (visitors). From this perspective, Devine's succinct description of the museum, from a practitioner's point of view, provides first-hand evidence for what, in the literature of marketing and consumer behavior, we know as co-construction of consumers' experiences in contemporary consumptionscapes (Peñaloza and Venkatesh 2006; Prahalad and Ramaswamy 2004; Shaw et al. 2011; Houston and Meamber 2011). The museum's success story also corresponds to Simon's $(2010$, ii) call for cultural institutions to "reconnect with the public and demonstrate their value and relevance in contemporary life." The Riverside also instantiates Fleming's $(2005,9)$ assertion that museums are "social constructs, and powerful ones at that, and they need to assume their place in the mainstream of contemporary life, not sit eccentrically on the margins." And with one million visitors in only five months after its opening, as Devine reports, the Riverside Museum is certainly not sitting quietly on the margins. Although geographically sitting gently on the bank of the River Clyde, socially, culturally, and psychologically, the museum is vigorously very present in the heart of society. It is an inevitable part of Glasgow's identity, one that constantly narrates Glasgow's history of transport and development. It is also a platform for visitors on which to play their own roles, stretch their wings of imagination, and tell and retell their biographical narratives of their past, present, and future. As such, the Riverside Museum owes its success to relating itself to people's contemporary life and creating value, not simply for them, but with them. Such value, as Devine stresses, is the outcome of seeing visitors as 'collaborator' in the co-creation of 'knowledge' and multiple forms of 'experience' in the museum.

Devine identifies four main motivational factors that drive cultural consumers' visits to the Riverside Museum. This diversity of motivations in people's visits to the museum is largely 
due to the 'multifaceted nature' of museums (Kotler et al. 2008). That is, museums attract people from diverse backgrounds who pursue different experiences in their visits. Therefore, depending on the type of visitor background, each of these motivational factors deserves to be discussed separately and in great depth; yet, given the relevance of the present manuscript to the topic of this special issue (Nostalgia in the Twenty-First Century), here we will focus on nostalgia as an overarching theme to encompass other relevant themes.

In order to better reflect on Devine's depiction of the museum, we visited the Riverside on different occasions and upon our non-participatory observations it became apparent that although the young and families (as Devine mentions) form a large proportion of the target audience, the demographic spectrum of the visitors is much wider than the museum primarily intended. The Riverside attracts people of varying age groups, including young adults, adults, and the elderly.

Amongst a variety of interesting points Devine highlights, we have been particularly drawn to three key interrelated themes: 1) reification of the past through the exhibits of the museum arouses nostalgic feelings in visitors and provides them with the opportunity to virtually walk into the past (both seen and unseen) and imagine different possibilities for the (sometimes same) past era. 2) This multiplicity of interpretations is the result of the spirit of 'storytelling' that prevails in the museum. On the one hand, the museum tells its own stories through unconventional methods of displaying exhibits; and on the other hand, visitors, as 'interpretive agents' (Arnould and Thompson 2005), are provided with the means (i.e., exhibits) to narrate their own stories. 3) Both of these seem to be the outcome of the museum's recognition of the fact that optimization of the visitors' experience depends on the maximization of their engagement with the content and context of the museum.

Our present discussion reflects on these three themes. Although the structure of the paper corresponds to the sequence of the above-mentioned points, the interrelatedness of these topics makes cross referencing inevitable. Apart from this introduction and the conclusion, our paper consists of three main sections. Firstly, after a brief review of the literature on nostalgia in the museum context, we discuss the importance of the phenomenon to individuals' everyday life narratives. We particularly focus on the relevance of nostalgia to the ongoing process of cultural 'reflexivity' (Giddens 1990) in contemporary society. We argue that for cultural consumers, nostalgia is not simply an aesthetic or emotional tour of the past made readily available to them via the objects of (experiential) consumption; rather, as a 'cultural practice' (Stewart 1988), nostalgia is a process of 'self-exploration' (Batcho et al. 2008) and 'sense-making' (Brown and Humphreys 2002) through juxtaposing past, present, and future. The museum-based historical representations, we argue, have the power to act as 'cultural referents' (Boym 2001) in individuals' navigation of self and identity. Secondly, we discuss the role of 'narratives' in cultural consumers' 'interpretations' of a plethora of 'meanings' (Shankar et al. 2001) embedded in the museum contents. Thirdly, we argue that the enhancement of visitors' nostalgic experiences and facilitation of their narrativization highly depend on the level of their 'engagement' (Prahalad and Ramaswamy 2004) with the museum contents and context.

\section{NOSTALGIA AND THE MUSEUM}

It is widely acknowledged (Davis 1979; Shaw and Chase 1989; Goulding 1999a, 1999b; Prior 2002) that museums are powerful venues that have the potential to arouse nostalgic feelings. Cultural places such as museums are one of the main areas where individuals (re)appropriate 
objects and images to (re)construct their sense of self and identity (Boym 2001; Goulding 1999a, 1999b; Joy and Sherry 2003). Nostalgia-based experiences in museums provide individuals with a process of 'sense making' (Brown and Humphreys 2002) through which they can relate to broader meanings of life and being. Realization of the potential meanings embedded in the museum exhibits, therefore, depends on individuals' past knowledge of the context to which the texts (the exhibits) belong and also the conditions in which these individuals themselves are presently contextualized.

For those who have 'lived' memories of the past (Davis 1979; Goulding 2001), the museum revives those memories. The museum becomes a workshop of identity and 'self-discovery' (Poulot 1994) where, upon turning the pages of their diary, participants recall their 'inspiring' or/and 'despairing' (Bonnell and Simon 2007) past. Based on visitors' individual and collective narratives of self (Brown and Humphreys 2002), such a workshop can create a variety of conflicting feelings of happiness, sadness, loss, reunion, rejuvenation, aging, pity, fear, pride, shame, guilt, absurdity, hope, esthetic pleasure, and recreation, to name but a few. These diverse feelings can also occur for those who have 'vicarious' experiences of the past (Davis 1979; Goulding 2001). For this second group, the past is only an 'imagined fabrication' based on the "objects, images and texts which can be seen as powerful talismans of how things used to be" (Shaw and Chase 1989, 9). Whilst the former group experience such feelings based on their personally lived memories, the latter refer to the repository of knowledge they have gained through formal and informal education. In either case, the feelings aroused in the museum context emerge from the convergence of the past with present and the implications of this conjunction for the future yet to come.

\section{Figure 1: Main Street (produced by authors)}

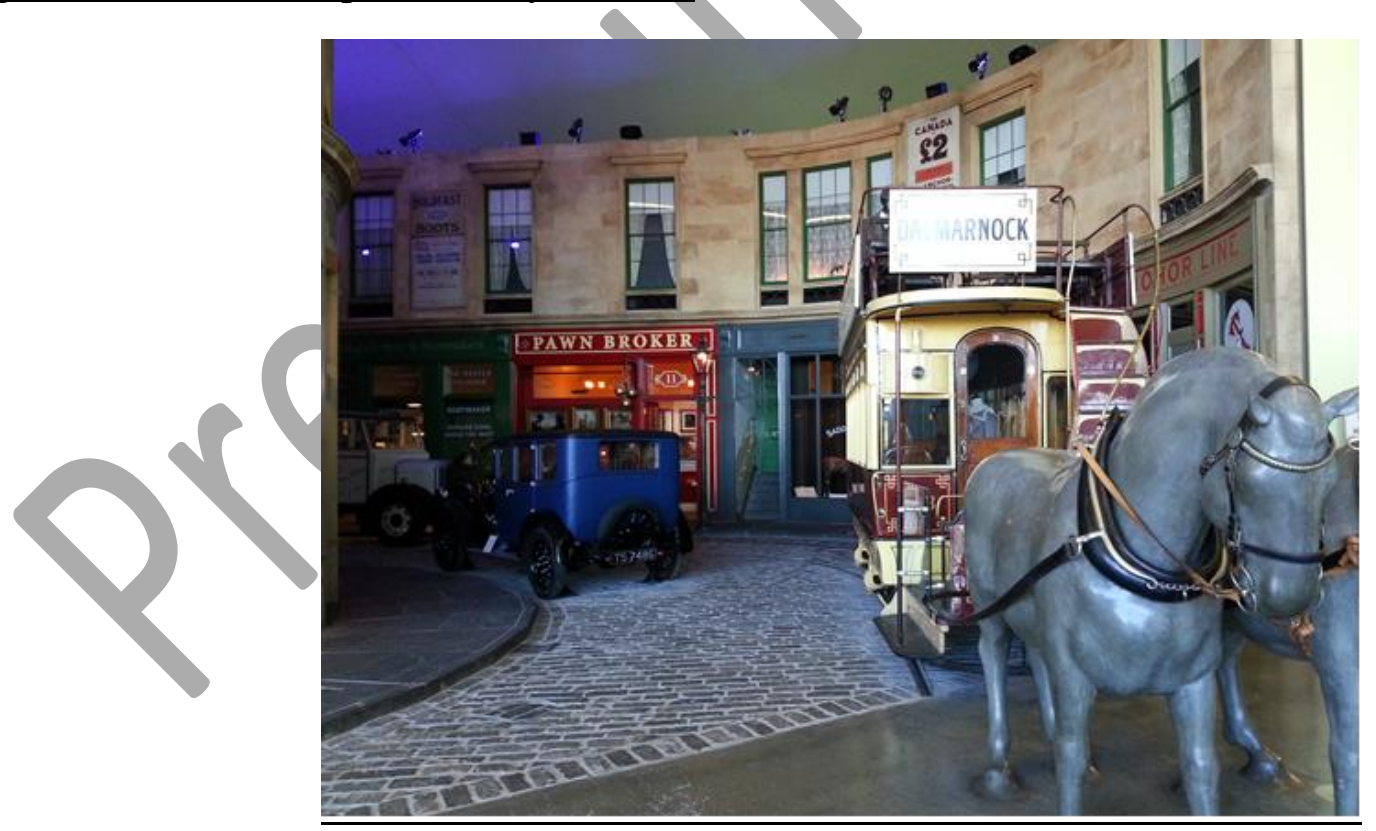

The Riverside Museum depicts such convergence and arouses different sensibilities and sensations in its visitors. The collection of old cars and trams, along with bicycles, motorcycles, and carriages reconstruct different images of a historical Glasgow. Stepping into Main Street and Kelvin Street (see Figure 1) also provides visitors with opportunities to travel in time and virtually experience how life used to be in those days. These historical entities act 
as time machines which invite visitors to get on board for multiple journeys in time. These journeys are facilitated by different catalysts such as auditory (e.g., the sound of the crowd in an old tram), tactile (e.g., the textile of the leather of old car seats), olfactory (e.g., the smell of charcoal in old locomotives), and visual (e.g., the video screens and the theatrical atmosphere of the museum) experiences. These catalysts can heighten visitors' experiences during their sense-making expeditions (Prentice 2001). Such experiences are further fuelled by the flow of information (e.g., newspaper quotes and citizens' letters on introductory panels) that help visitors to better visualize and immerse in the physical context of the past they are about to imagine and travel to. A key characteristic of the Riverside Museum, as Devine rightly elaborates, is that these exhibits are meant to tell different tales of a historical Glasgow, as it was, without 'sanitizing' the past:

"There was a desire to accurately portray both the positive and negative aspects of the city. We did not want to sanitise the past but rather to challenge visitors' assumptions or perceptions of that time period. For this reason Main Street, Riverside tackles subjects including poverty, racism, disease, infant mortality, violence as well as providing information on general living conditions and traffic."

As the extant literature alludes to, nostalgia may be directed toward or associated with 'romanticization' (Casey 1987; Goulding 1999b), 'aestheticization' (May 1996), 'sanitization' (Goulding 1999b), or 'utopianization' (Davis 2010) of the past. These forms of nostalgia can be viewed as a 'sentimental' and 'romanticized' (Goulding 199b) depiction of history at the expense of cleansing the past, or what Stewart (1988) refers to as 'naturalization' of a history, which is depleted of its dark sides under the skin of 'handsome' and 'well-kept' environments. The Riverside Museum seems to distance itself from 'manipulating' (Hewison 1987, in Goulding 1999b) history. It seeks to instigate a 'realistic nostalgia' (Gershenson 2005) that could truthfully mirror the past with all its bright and dark sides, and leave the judgement to the visitors. Entrenched in its 'bittersweet quality' (Casey 1987), this realistic nostalgia can prompt diverse sensitivities and sensibilities about a past era. Such portrayal of a historical past is not ahistorical; it is not simply based on building a public space as "a postmodern village of the imagination" and "fantasy environments to roam around in" (Stewart 1988, 231-232). The representations of a historical past presented at the museum are geared toward providing the visitors with only toolkits to derive their own personal interpretations of the past.

The 'nostalged past' (both time and place) the Riverside Museum portrays is one we cannot really rejoin. "We cannot rejoin it precisely because we cannot re-experience it in propria persona [italics original], even if it has left tantalizing marks in the present" (Casey 1987, 365). The Riverside Museum's Glasgow, in real terms, is impossible to re-enter simply because it "has effectively vanished from our lives and of which" we are "reminded by its extant traces" (ibid). Yet, the virtual reunion has indeed been made possible. Visitors walk around in the museum and, based on their personal assumptions, compose their own tales about a historically time-and-place-bound Glasgow that no longer exists.

As Devine affirms, and we stated in the beginning of this paper, people visit the museum for different reasons, including nostalgia. Some of the evidence Devine presents in her account (e.g., quotes about remembering one's car and its registration number) explicitly exemplify more common forms of nostalgia (e.g., existential, esthetic, collective) (see Holbrook 1993; 
Schindler and Holbrook 2003; Goulding 1999b), but her brief reference to avoiding sanitization of the past directs us to the reflexive potential of nostalgia, a less visible aspect of the phenomenon. Nostalgia, as the existing literature also alludes to, can be rooted in people's deeper and sometimes 'episodic' and 'semiconscious' (Polkinghorne 1988, in Brown and Humphreys 2002,142) reflections on self and identity projects. This type of nostalgia can be highly 'reflexive', one which is different from collective and conscious (meta)narratives of national and communal identities, and can be experienced at an 'individual' level in everyday life situations (Boym 2001). Reflexive nostalgia, as we will discuss in the next section, is vital to individuals' cultural reflexivity and project of 'self' and 'sense-making' in contemporary life. In our view, this dimension of the museum is highly relevant to the discourse and positioning of museums in the twenty-first century.

\section{NOSTALGIA AND CULTURAL REFLEXIVITY}

One of the key dilemmas faced by contemporary society is the question of identity (Giddens 1991). As Goulding (1999b, 648) emphasizes, "the popularization of heritage" and the rise of "a nostalgia boom which has crept into the shopping and leisure activities of the general public", in the UK context for example, can explain the emergent quest for identity in contemporary society. In the general conditions of modern life, where mankind is often "fragmented, alienated, deconstructed, confused and torn between multiple roles and responsibilities" (ibid), nostalgia can act as an anchor to help to stabilize human beings' wandering vessel of self and identity. Nostalgia-based museums can provide us with images and artifacts from past eras as "powerful symbols by which we may listen to the past and locate ourselves in the present" (ibid). "Nostalgia helps us to take stock of our lives and past accomplishments...thus placing us in time and space in ways which permit a better understanding of ...who and where we are presently" (Brown and Humphreys 2002, 143). As Stewart $(1988,229)$ nicely puts it, in contemporary society and in the conditions of (post/late/high) modernity, nostalgia plays a significant role in navigating our sense of self:

"Once, where there was a time and a place for everything, there was also a time and a place for nostalgia. But now, threatened with a deadening pluralism that makes us all just an 'other' among others..., in which difference erases into an utter indifference..., and where the self is a pastiche of styles glued to a surface, nostalgia becomes the very lighthouse waving us back to shore - the one point on the landscape that gives hope of direction."

Nostalgia is an opportunity for us to stop to ponder; it "enable[s] us to escape the mindless crippling rush onward of modernity" (Schönle 2010, 90). It makes us undergo a process of reflexivity, where we can make sense of our present lives in the light of the knowledge we have and/or gain about the past. Such incoming knowledge about the past in Davis' (1979) view can result in three 'orders' of nostalgic experience: 1) emotional nostalgia: an expressive feeling related to the idea of 'good old days' and yearning for a past which will never come back 2) reflexive nostalgia: self-conscious scrutinization of the past in pursuit of understanding the conditions of life in those days 3) analytical nostalgia: an interpretive exploration of self in order to understand the reason for feeling nostalgic. Whilst Davis' first order is associated with a simple sentimental experience, his second and third orders imply a 'conscious' course of reflexivity, a process of examining the past and self respectively. Yet, reflexivity, as Giddens $(1984,3)$ asserts, "should be understood not merely as 'selfconsciousness' but as monitored character of the ongoing flow of social life." Reflexivity, as 
an 'indispensable' part of human nature (Archer 2007), drives individuals toward carefully observing both their own life conditions and those of others'. As 'purposive agents', human beings can monitor their own lives, the conditions of the context in which they live, and also the life conditions of those they compare themselves with (Giddens 1984). And museums provide a fertile ground for such reflexivity. They bring the representations of a historical past to the vanguard of the very present, where individuals can engage with self-examination. Upon reflexive exposure to the relics of a past context and its habitants, cultural consumers, as both culture 'bearers' and culture 'generators' (Arnould and Thompson 2005), can embark on exploring themselves and their 'biographical self' (Giddens 1991).

This biographical self, in essence, is a 'narrative' that encompasses one's constant examination of his/her actions over a lifespan (Giddens 1990). One's reflexive identity is an ontological (re)negotiation through 'internal conversations' (Archer 2007), in which the person has to answer the fundamental question of 'how shall I be?' in the future (Giddens 1991). This means that reflexivity goes beyond just 'self-understanding'; "we are not what we are, but what we make of ourselves" (Giddens 1991, 75). Reflexivity is "far more than just getting to know oneself better"; it is "subordinated to the more inclusive and fundamental aim of building/rebuilding a coherent and rewarding sense of identity" (ibid). That is, the project of self needs consistency in relation to past, present, and future.

As earlier discussed, the Riverside Museum provides a convergence point in time to compose a biographical storyline juxtaposing past, present, and future. What seems to be now 'old' in the Riverside Museum was the old's 'new'. The now antique used to be the antique's now or even avant-garde. Interestingly, given the nature of the exhibits in the museum (vehicles of transport and travel), these exhibits - which at first glance seem to be statically sitting in a frozen slice of time and space in the museum - are symbolically dynamic for two reasons: 1) they are selectively picked by the museum to go on display and they only partially 'signify' (Fitchett and Saren 1998) a historical past that no longer exists in its entirety; therefore, the exhibits are only partial representations. 2) The means of transport on display (e.g., cars, trams, and ship models) can also symbolize 'mobility' (Johinken 2009) and the progression of transformation in the course of time and space. Locating this symbolism in the context of contemporary life recalls Habermas' (1997) analysis of modernity as 'unfinished project', meaning that modernity sustains through its constant engagement with the past. The past experienced its own modernity through engagement with its own then past. Such a relationship also applies to the present. What is now's new will be the future's old. Take, for example, the modern vehicles visitors park outside the museum. With the rapid development of technology, such vehicles will soon be regarded as (very) old. Therefore, a characteristic feature of the modern is the "the moment of novelty, the New, which will itself be surpassed and devalued in turn by the innovations of the next style[s]" (Habermas 1997, 39).

An implication of this analysis to the cultural experiences of the Riverside Museum visitors can be that nostalgia is not merely about a historical past; it could also be about a historical present. If visitors view the past as passé, they should also see the present as soon-to-be passé in relation to the near or distant future. Since during their visit to the museum, individuals may feel "stifled within the conventional confines of time and space" (Boym 2010, 59), they should be able to extend the boundaries of their dreamscapes to appreciate the temporality of the time and space they are currently living in. Even further, they can feel nostalgic about the future they may or may not experience. This reflection on the relationship between the three episodes of past, present and future can therefore enhance their reflexive monitoring of their 
sense of being. For them, nostalgia can act as a "means of maintaining a collective sense of socio-historic continuity, a source of resistance to hegemonic influence and a defence against [the] anxiety [and mad rush of modernity's normativity]" (Brown and Humphreys 2002, 141). But simultaneously and at an individual level, it can also be a process of cultural and social reflexivity that is both 'retrospective' and 'prospective' (Boym 2001) and resides within the individual's everyday life, both affecting and being affected by them.

Here, we should emphasize that what we have discussed so far is not meant to reflect a normative analysis of nostalgia. On the contrary, we have sought to highlight the fact that nostalgia has the potential to arouse a wide spectrum of senses and sensibilities in the museum visitors. Nostalgia, as Stewart $(1988,227)$ posits, is "a cultural practice, not a given content; its forms, meaning, and effects shift with the context." Devine clearly argues that the 'creation of knowledge' in the context of the museum is not a simple act of memorizing museum facts. By relating nostalgia to the reflexive project of self and identity, we endeavored to demonstrate the deeper and sometimes hidden layers of this knowledge creation and sense-making through individuals' nostalgic engagement with the museum. As we will explain further in upcoming paragraphs, visitors' narrativization of the meanings they derive from the museum exhibits plays a pivotal role in their nostalgic experiences.

\section{NOSTALGIA, NARRATIVITY, AND THE MUSEUM}

Gurian (2006) identifies five types of museum orientations: object-centred (focus on collections), narrative-centred (evocative of feelings), client-centred (offer variety of experiences), community-centred (local relationships) and national museums (represent national values). Gurian's taxonomy may help to generally classify museums based on their positioning, and from a managerial perspective, but such a narrow typology should not be viewed and used as 'matricization' of visitors and their multifaceted experiences and sensemaking capacity. In other words, the type of experience(s) and meanings visitors derive from the museum contents cannot be, in a one-way road, determined by the museum. As we will discuss in the following paragraphs, visitors - as the authors of their own narratives - can construct their own experiences and meanings. As such, narratives can be evocative of not only feelings and experiences, but a wide range of teleologies that are deeply associated with the museum contents and context.

With this in mind, Devine's report clearly indicates that the Riverside Museum is narrativeoriented. Storytelling is one of most important success factors of the museum:

"This success is in part due to...our display approach of 'storytelling'. Storytelling is a fundamental tenet of the exhibition philosophy for Riverside. It represents a move away from more traditional techniques of displaying objects by collection type or a defined chronology. Telling stories about specific objects is an approach which we believe encourages a depth of analysis and avoids bland summaries. Each display has one key message which summarizes the story and an identified target audience for which all interpretation is defined and developed."

This statement concurs with the existing literature's (Holt 2004; Megehee and Woodside 2010; Woodside and Megehee 2010) emphasis on the role of storytelling in consumers' engagement with the object of consumption. Consumers "achieve deeper understanding of 
themselves via the stories they tell to themselves and others in comparison to not retelling their experiences" (Woodside and Megehee 2010, 425). They are more likely to remember a story and to relate the story to experiences they gain or have already stored in their memory. This storytelling capacity is a distinct feature of human beings who are capable of seeing the present rising out of a past, heading into a future and observing reality in narrative forms (Novak 1975). And museums are excellent places for the operationalization of this capacity.

Any piece of text, sign, object, or artifact potentially has a story to tell. As useful means, each of these can help visitors to construct their own narratives. Such artifacts, "are not only valued because they signify that they were once used, they are also valuable because they can be used as signifiers" (Fitchett and Saren 1998, 332). In the context of history museums such as the Riverside, where historical representations prevail, objects become particularly significant sources of storytelling. Artifacts and exhibits carry with them myriad stories. These objects and their surrounding contexts speak of the time they belong to, the people of their era, the socio-cultural, economic and political conditions in which they existed. Whilst these objects have potential stories to be told, the act of telling also depends on their audience. As apparently silent texts of historical signification, they need to be recited. These texts are not simply fixed sources of explicit, normative, and informative knowledge to be transferred in a one-way tradition from the exhibits to the readers; they comprise a host of implicit messages to be decoded by their readers. Each exhibit becomes a musical instrument to be played by the artist, the visitor; and depending on their music notes and tastes, each artist can vocalize the instrument in a different way.

"To narrate is to place oneself in an event and a scene - to make an interpretive space - and to relate something to someone [or something]: to make an interpretive space that is relational and in which meanings have direct social referents" (Stewart 1988, 227). "Stories and storytelling help us to make sense of our lives"; they are "the (italics original) most important means by which our experiences are made meaningful" (Shankar et al. 2001, 429). "We learn about who we are, our history and our culture through stories and by telling stories" (ibid, 431).

The Riverside Museum is a case which presents 'historical accounts' of people's stories and imagination of the past (Chronis and Hampton 2003). Here, in the museum, imagination is activated to give way to people's construction of their narratives (Chronis et al. 2012). The past is reincarnated as "a picture pieced together from the available accounts and artifacts remaining from the past" (Goulding 2000a, 847). As a site of cultural heritage, the museum avails the visitors with only canvas on which to draw their own paintings of a past they can imagine or remember. Here, visitors are not just passive audiences; they also become authors, interpreters, and critics of their own (sometimes new) stories. They are not passive or uncritical recipients of information about the past (Bagnall 2003; Cova and Cova 2012). These individuals become actively involved in "heritage interpretation that is justified by their need to bring a closure in cultural narratives" (Chronis and Hampton 2003, 355). These narratives are not necessarily collective in nature; they are also in tune with people's individual and very local experiences (Carnegie 2010). The sample quotes Devine refers to in her article clearly exemplify such narratives at an individual level:

"I bring my grandchildren, and I like it myself. My father used to drive the trams, it's kind of nostalgic." 
"I like the nostalgic bit. You can show your kids this was out when we were your age and so on."

These examples demonstrate the embeddedness of nostalgia in individuals' everyday life. They are not necessarily "socio-culturally derived metanarratives" authored by the museum; rather they are very "individually constructed" (Shankar et al. 2001, 439) narratives based on the visitors' own personal relationships with the museum contents. As we discussed earlier, the museum has the capacity to open up a variety of routes to individuals' storytelling. For example, one of the quotes in Devine's paper reads:

"I don't think Glasgow had seen so many people for a long, long time.

Maybe VE Day would have been the last time Glasgow was as busy.

It was just full of people, you couldn't move. Very exciting. Electric. I

know they were electric trams but the atmosphere was electric.'

Narratives of this kind suggest that such individual narratives are not completely divorced from collective forms of remembrance. Those who were present at the particular event of Glasgow's farewell to its trams $\left(4^{\text {th }}\right.$ September 1962$)$ will certainly have a collective memory of that day. Therefore, with a focus on personalization of narratives, we are not, by any means, suggesting that people's narratives are entirely depleted of collective associations with the past. Instead, what we emphasize here is that the power of authorship, as Shankar et al. (2001) also contend, lies in the hands of the individuals' as storytellers. The spirit of collectivism we witness in this particular case is not necessarily a metanarrative, something like a sense of ethnocentrism or nationalism that might underpin people's emotional association with a war museum. This sense of collective remembrance does not, as a constitutive element, dominate individuals' narratives of self; rather, alongside other themes such as very personal emotional accounts of tram spotters, it itself becomes part of the individuals' stories. In the following section, we will explicate the importance of engagement to facilitation of such narratives and enhancement of visitors' nostalgic experiences with the objects of consumption.

\section{ENGAGEMENT AND CO-CREATION OF NOSTALGIC EXPERIENCES}

Sometimes, solutions can paradoxically turn into problems. Offering solutions can sometimes decrease the level of creativity and suppresses imagination. In the age of experiential consumption, ready-made solutions can render consumers powerless and bored audiences. In the era of 'theatres of consumption' (Firat and Dholakia 1998), consumers want to be on the stage rather than simply watch, from their seats, actors play on the stage. Consumers' detachment from the stage can therefore result in feelings of agitation, exclusion, and alienation. In Grant's $(2000,123)$ words, in our modern consumption spaces, "people expect to have a part to play and, when they don't, they feel shut out."

Such metaphors can be extended to a majority of experiential contexts including the museum. Museum visitors are interested in co-creating their experiences (White et al. 2009). They want to be seen as participants and not just idle audiences who stand aside and watch the game take place on the stage. Visitors and museums both can benefit from this willingness to participate. Whilst visitors can have better experiences in their cultural consumption, museums can equally channel their activities toward enhancing such experiences and augment their image and value propositions (Cova and Cova 2012; Prahalad and Ramaswamy 2004). Achieving this balance, as the literature suggests (e.g., Falk and Dierking 
1997; Kotler et al. 2008; Simon 2010), depends on the quality of visitors' engagement with the museum contents.

Figure 2: A Fire Engine Interactive Panel for Children (produced by the authors)

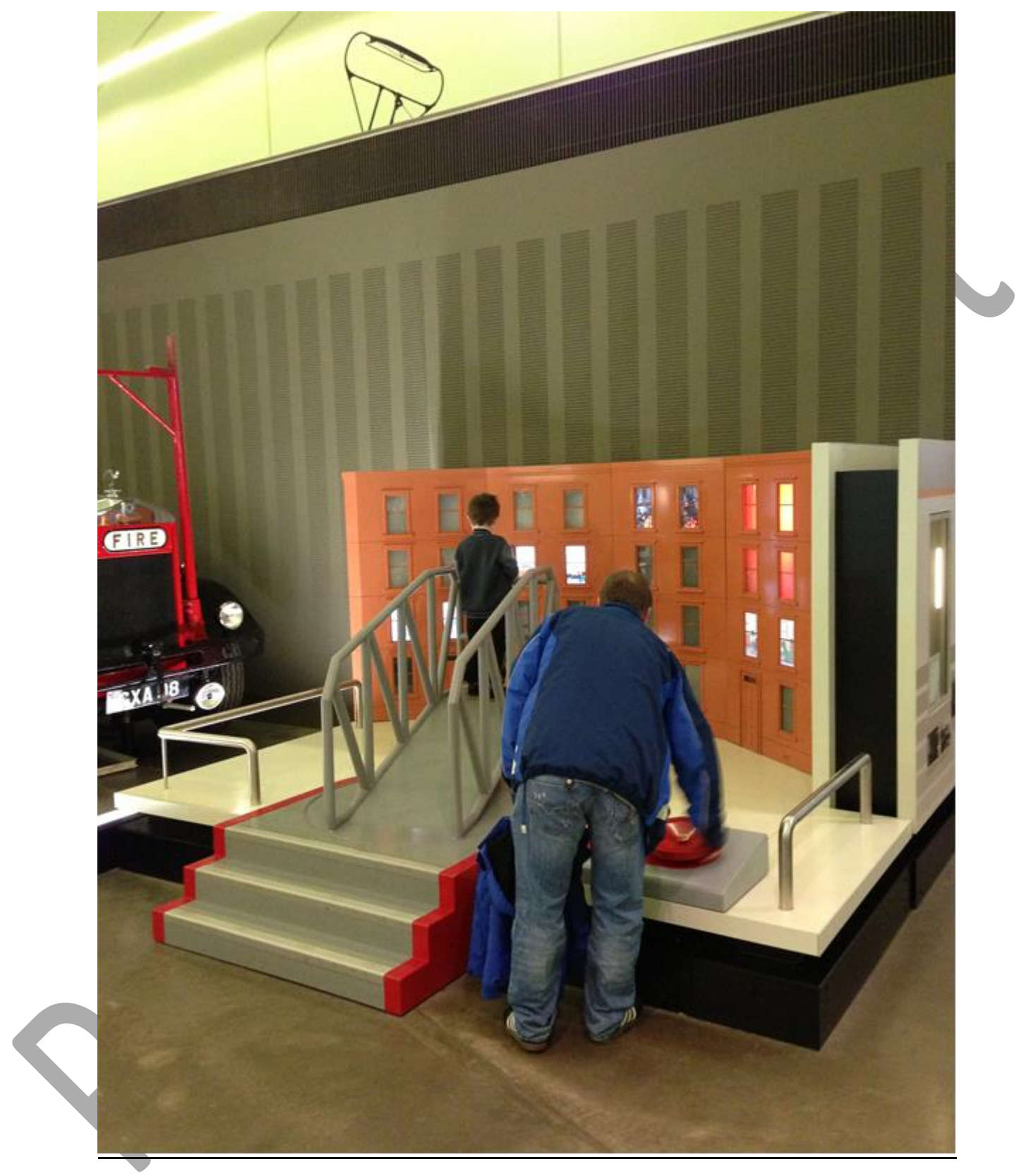

The Riverside Museum, as Devine explains and our observations also confirm, acknowledges this vital approach. The objects on display are accompanied by a series of complementary equipment such as information panels, video screens, light and sound effects, games (Figure 2 ), and vibration technology used in one of the trams. Visitors, therefore, have a reasonable amount of accessories to be able to engage with the museum objects. Yet, as Edmonds et al. (2006) also contend, the level of engagement is also closely related to the visitors' interaction orientation; whilst some people are (pro)active in their engagement with the museum, others might need to be guided and assisted in their visits. Therefore, given the diverse backgrounds 
of visitors and the motives that underpin their consumption experiences, it becomes difficult for the museum to thoroughly meet all visitors' experiential expectations.

Figure 3: Collection of Vehicles \& Trams (produced by the authors)

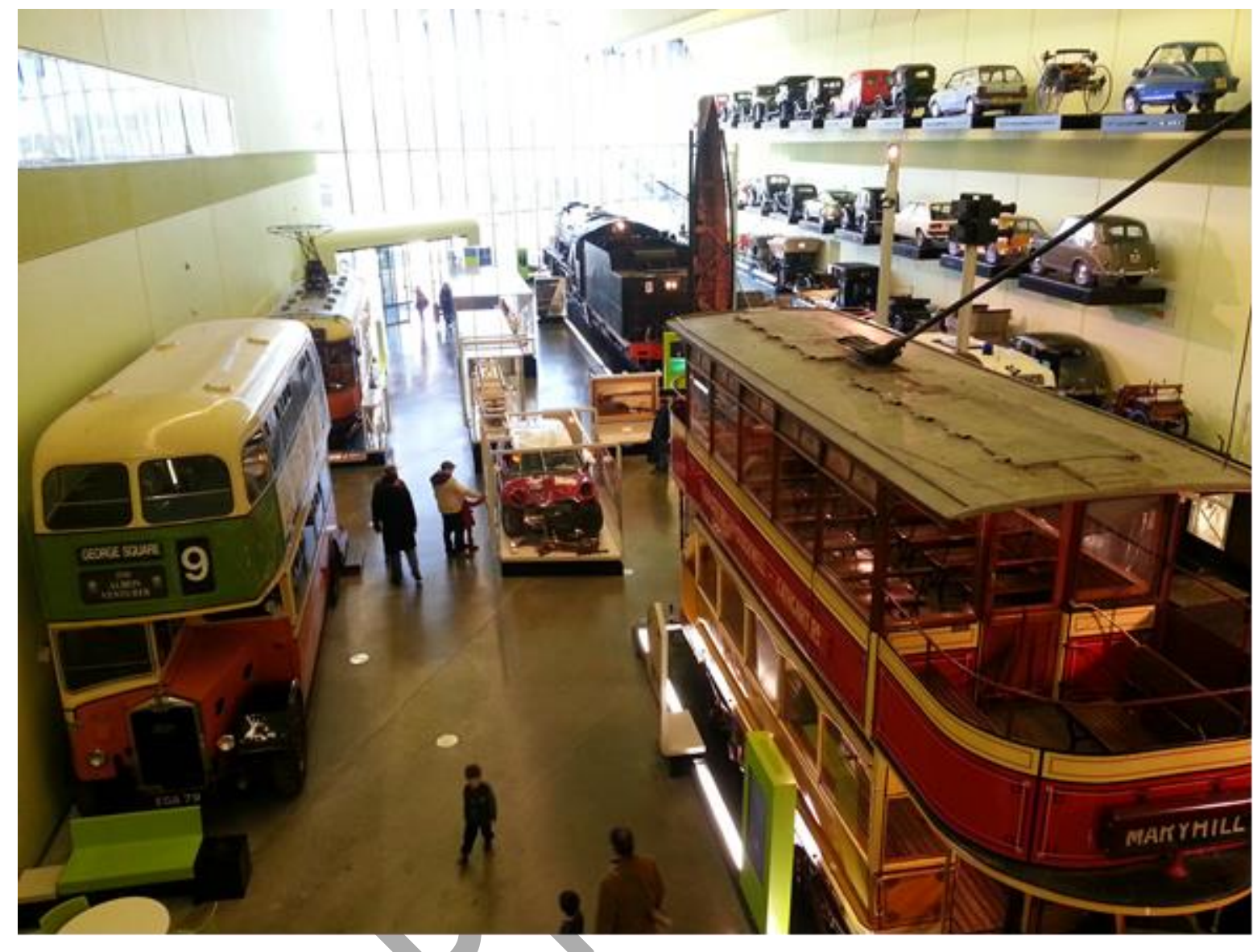

For example, the layout of the Riverside Museum does not follow any particular order (based on chronology or collection types) as they are presented in a mixed manner (Figure 3). Earlier we referred to Devine's explicit justification of the museum's approach to this kind of display: the rationale being that visitors are supposed to develop their own stories as each object has its story. But some visitors, as the following comment from one of the museum's visitors indicates, may seek guidance in their visits:

"When I arrived at the museum, I asked one of the friendly staff members whether there was an audio tour, or if not where I should start on my journey round the museum, so as not to miss any highlights. 'Oh,' she said, 'you just start anywhere and go anywhere, it's not really connected.' And despite the glory of the material on view here, and the obvious affection for it shown by the packed firstday crowds, the truth is that without that sense of connection and context, even the most magnificent objects lose some of their power, and speak to us much less clearly than they should." (Scotsman 2011)

This statement provides strong evidence for the fact that engagement is a two-way road. Engagement refers to the level and type of interaction and involvement individuals undertake in their consumption situations (Achterberg et al. 2003; Higgins and Scholer 2009; Abdul- 
Ghani et al. 2011). In the context of the museum, this engagement partially depends on visitors' enthusiastic focus on the artifacts and exhibits and interaction with(in) the museum context. Even in the case of surreal museums, reposed on their imagination, visitors can willingly suspend their sense of disbelief ${ }^{\mathrm{i}}$ and engage with the museum content and context. This kind of willingness can magnify the level of enjoyment, excitement, or any other emotional uptake one can derive from the museum environment. For example, in visiting museums of simulated horror (e.g., the London Dungeon), although visitors know in advance that the atmosphere of the museum is not real and does not impose any threat on them, they willingly give up this notion of unreality and immerse themselves in the experience of horror the venue intends to create. The experience of horror is therefore partially dependent on the level of visitors' willingness to being horrified.

Whilst visitors' willingness is important to fostering engagement and the creation of memorable experiences, museums too have a great role to play in this mission. This task is mainly related to the 'facilitation of engagement' (Taheri and Jafari 2012). The collection of exhibits should be more than window-dressing in a museum. In displaying their objects, museums should focus on the stories visitors bring out, and in doing so, guidebooks, signage, role plays, video screens, sound and light effects can provide extra means of enhancing visitors' engagement with(in) the museum (Black 2009; Kotler et al. 2008; Prentice 2001). The decision on selecting the most appropriate approach to object display should be based on the messages to be communicated with, and also the meanings to be created by, visitors (Bourdieu and Darbel 2008; Fitchett and Saren 1998).

As mentioned earlier, the Riverside Museum has already used a series of equipment to facilitate visitors' engagement with the exhibits. This may be fine for some visitors, but just too much for others to cope with, thereby impacting on the process of co-creation of experience, impeding the ability to be reflexive or draw upon individual or collective nostalgic memories. The above quote from the Scotsman newspaper explicitly indicates that some visitors may require further assistance to fully explore the experience, rather than being told that they can go anywhere or start anywhere. This kind of visitors need to be assisted in their co-creation of nostalgic experiences and narrativization of self.

The co-creation of experience, as the extant literature affirms, is closely related to cultural consumers' characteristics and motives. As Ooi (2002) reminds us, visitors interpret cultural products through their own lens; hence, their worldviews contribute to the operant resources they use in co-creating their experience. Individuals with more prior knowledge and experience about the museum enjoy higher levels of engagement than those less knowledgeable (Black 2009; Fienberg and Leinhardt 2002). Similarly, regular visitors are more likely to seek deeper levels of engagement during their visit (Black 2009). Previous experience, as Goulding (1999a) contends, may come not from previous visitation to the museum itself, but from awareness and knowledge of the exhibit itself. These characteristics therefore affect the way visitors personalize the museum's meanings and message(s). As such, the Riverside needs to continue rigorous research to find out about its varying visitors' experiential preferences and ways of engagement. 


\section{CONCLUSION}

Our purpose in this paper has been to shed some theoretical light on Devine's account of the Riverside Museum. We do not, by any means, claim that our discussion is a definitive reflection on her report. Since the Riverside Museum is about storytelling, narratively speaking, this paper is our narrative of Devine's narrative. Undoubtedly, Kirsty Devine and her colleagues at the Riverside Museum and other stakeholders have undertaken a large amount of hard work to bring the museum to its current shape. Based on their invaluable expertise and experience, they have also rightly identified the potential of nostalgia in bringing colorful meanings to people's everyday lives. The meanings, emotions, and sensibilities which reciprocally create and are created by nostalgia are too diverse to be discussed in one single article. As emphasized by other contributors of this special issue, nostalgia is one of the most interesting and, of course, important topics in the $21^{\text {st }}$ century. And museums have a great role to play in this domain. As Stewart $(1988,228)$ asserts, "meaning can only be made and read in a 'context' that is not just a 'background' for the 'text' but its very inspiration - its enabling condition." Museums provide the context for visitors to not only derive meanings from objects but also create their own meanings based on their narratives of self. From this perspective, museums both enable and inspire people to engage in meaningful narratives of life, both individually and collectively.

\section{Acknowledgements}

We are grateful to Derek Bryce and the five editors of this special issue for their useful comments on the earlier version of this paper.

\section{References}

Abdul-Ghani, Eathar, Kenneth F. Hyde, and Roger Marshall. 2011. Emic and etic interpretations of engagement with a consumer-to-consumer online auction site. Journal of Business Research 64, no. 10: 1060-66.

Achterberg, Wilco, Anne M. Pot, Ada Kerkstra, Marcel Ooms, Martien Muller, and Miel Ribbe. 2003. The effect of depression on social engagement in newly admitted Dutch nursing home residents. The Gerontologist 43, no. 2: 213-18.

Archer, Margaret S. 2007. Making our Way through the World. New York: Cambridge University Press.

Arnould, Eric. J., and Crege J. Thompson. 2005. Consumer culture theory (CCT): Twenty years of research. Journal of Consumer Research 31, no. 4: 868-82.

Bagnall, Gaynor.2003. Performance and performativity at heritage sites. Museum and Society 1, no.2: 87-103.

Batcho, Krystine Irene, Meghan L. DaRin, Andrea M. Nave, and Renée R. Yaworsky. 2008. Nostalgia and identity in song lyrics. Psychology of Aesthetics, Creativity, and the Arts 2, no. 4: 236-44.

Black, Graham. 2009. The engaging museum: Developing museums for visitor involvement. London: Routledge.

Bonnell, Jennifer, and Roger I. Simon. 2007. "Difficult" exhibitions and intimate encounters. Museum and Society 5, no. 2: 65-85. 
Bourdieu, Pierre, and Alain Darbel. 2008. The love of art: European art museums and their public. Trans. Caroline Beattie, and Nick Merriman. UK: Polity Press.

Boym, Svetlana. 2010. Ruins of Avant-Garde: From Tatlin's tower to paper architecture. In Ruins of Modernity, ed. Julia Hell and Andreas Schönle, 58-88. Durham, NC: Duke University Press.

Boym, Svetlana. 2001. The future of nostalgia. New York: Basic Books.

Brown, Andrew D., and Michael Humphreys. 2002. Nostalgia and the narrativization of identity: A Turkish case study. British Journal of Management 13, no. 2: 141-59.

Bryman, Alan. 2008. Social Research Methods (3rd ed.). UK: Oxford University Press.

Carnegie, Elizabeth. 2010. Museums in society or society as a museum? Museums, culture and consumption in the (Post)Modern world. In Marketing the arts: A fresh approach, ed. Daragh O'Reilly and Finola Kerrigan, 231-39. Wolverhampton: Routledge.

Casey, Edward S. 1987. The world of nostalgia. Man and World 20, no. 4:361-84.

Chronis, Athinodoros. 2005. Our Byzantine heritage: Consumption of the past and its experiential benefits. Journal of Consumer Marketing 22, nos. 4-5:213-22.

Chronis, Athinodoros, Eric J. Arnould, and Ronald D. Hampton. 2012. Gettysburg reimagined: The role of narrative imagination in consumption experience. Consumption Markets \& Culture, DOI:10.1080/10253866.2011.652823.

Chronis, Athinodoros, and Ronald D. Hampton. 2003. Baudolino at the edge of history: Narrative construction and narrative closure in a heritage museum. Advances in Consumer Research, ed. Punam Anand Keller and Dennis W. Rook 30: 355-56. Vadosta, GA: Association for Consumer Research.

Cova, Bernard, and Véronique Cova. 2012. On the road to prosumption: Marketing discourse and the development of consumer competencies. Consumption Markets \& Culture. iFirst.

Davis, Fred. 1979. A yearning for yesterday: A sociology of nostalgia. London: Collyer MacMillan.

Davis, Teresa. 2010. Third spaces or heterotopias? Recreating and negotiating migrant identity using online spaces. Sociology 44, no. 4: 661-77.

Edmonds, Ernest, Lizzie Muller, and Matthew Connell. 2006. On creative engagement. Visual Communication 5, no. 3: 307-22.

Falk, John H., and Lynn D. Dierking. 1997. The museum experience. Washington, D.C.: Whalesback Books.

Fienberg, Joyce and Gaea Leinhardt 2002. Looking through the glass: Reflections of identity in conversations at a history museum. In eds. Gaea Leinhardt, Kevin Crowley and Karen Knutson. Learning Conversations in Museums, 167-212. Mahwah: Lawrence Erlbaum Associates.

Firat, Fuat A., and Nikhilesh Dholakia. 1998. Consuming people: From political economy to theaters of consumption. London: Routledge.

Fitchett, James A., and Mike Saren. 1998. Baudrillard in the museum: The value of Dasein. Consumption Markets \& Culture 2, no. 3: 233-35.

Fleming, David. 2005. Managing change in museums. Paper presented at the museum and change international conference, November 8-10, in Prague, Czech Republic.

Gershenson, Olga. 2005. Gesher: Russian theatre in Israel - a study of cultural colonization. New York: Peter Lang Publishing Inc.

Giddens, Anthony. 1984. The constitution of society: Outline of the theory of structuration. Cambridge: Polity Press.

Giddens, Anthony. 1990. The consequences of modernity. Cambridge: Polity Press.

Giddens, Anthony. 1991. Modernity and self identity. Cambridge: Polity Press. 
Goulding, Christina. 1999a. Contemporary museum culture and consumer behaviour. Journal of Marketing Management 15: 647-71.

Goulding, Christina. 1999b. Heritage, nostalgia, and the "grey" consumer. Journal of Marketing Practice: Applied Marketing Science 5, nos. 6/7/8: 177-99.

Goulding, Christina. 2000. The commodification of the Past, Postmodern Pastiche, and the search for authentic experiences at contemporary heritage attractions. European Journal of Marketing 34, no. 7: 835-53.

Goulding, Christina. 2001. Romancing the past: Heritage visiting and the nostalgic consumer. Psychology \& Marketing 18, no. 6: 565-92.

Goulding, Christina. 2003. Issues in representing the postmodern consumer. Qualitative Market Research: An International Journal 6, no. 3: 152-9.

Grant, John. 2000. The new marketing manifesto: The 12 rules for building successful brands in the 21 st century. UK: Thomson.

Gurian, Elaine Heumann. 2006. Civilising the museum: The collected works of Elaine Heumann Gurian. London: Routledge.

Habermas, Jürgen. 1997. Modernity: an unfinished project. In eds. Maurizio Passerin d' Entreves and Seyla Benhabib. Habermas and the unfinished project of modernity. 38-55. Cambridge, MA: The MIT Press.

Higgins, Tory E., and Abigail A. Scholer. 2009. Engaging the consumer: The science and art of the value creation process. Journal of Consumer Psychology 19, no. 2: 100-14.

Holbrook, Morris B. 1993. Nostalgia and consumption preferences: Some emerging patterns of consumer tastes. The Journal of Consumer Research 20, no. 2: 245-56.

Holt, Douglas. 2004. How brands become icons. Cambridge, MA: Harvard University Business School Press.

Houston, H. Rika, and Laurie. A. Meamber. 2011. Consuming the "world": Reflexivity, aesthetics, and authenticity at Disney World's EPCOT Center. Consumption Markets \& Culture 14, no. 2: 177-91.

Johinken, Rebecca. 2009. Not quite Mad Max: Brian Trenchard- Smith's Dead End Drive-In. Studies in Australasian Cinema 3, no. 3, 309-20.

Joy, Annamma, and John F. Jr. Sherry. 2003. Disentangling the paradoxical alliances between art market and art world. Consumption Markets \& Culture 6, no. 3: 155-81.

Kotler, Neil, Philip Kotler, and Wendy I. Kotler. 2008. Museum marketing \& strategy: Designing missions, building audiences, generating revenue \& resources. 2nd ed. USA: Jossey-Bass.

May, Jon. 1996. Globalization and the politics of place: Place and identity in an Inner London neighbourhood. Transactions of the Institute of British Geographers New Series 21, no. 1: 194-215.

Megehee, Carol M., and Arch G. Woodside. 2010. Creating visual narrative art for decoding stories that consumers and brands tell. Psychology and Marketing 27, no. 6: 603-22.

Ooi, Can-Seng. 2002. Cultural Tourism \& Tourism Cultures: The Business of Mediating Experiences in Copenhagen and Singapore. Copenhagen: Copenhagen Business School Press.

Peñaloza, Lisa and Alladi Venkatesh. 2006. Further evolving the new dominant logic of marketing: from services to the social construction of markets. Marketing Theory 6, no. 3: 299-316.

Poulot, Dominique. 1994. Identity as self-discovery: The ecomuseum in France. In Museum culture: histories, discourses, spectacles, ed. Daniel J. Sherman and Irit Rogoff, 66-84. London: Routledge. 
Prahalad, C. K., and Venket Ramaswamy. 2004. The future of competition: Co-creating unique value with customers. Cambridge, MA: HBS Press.

Prentice, R. 2001. Experiential cultural tourism: Museums and the marketing of the new romanticism of evoked authenticity. Museum Management and Curatorship 19, no. 1: 526.

Prior, Nick. 2002. Museums and modernity: Art galleries and the making culture. Oxford: Berg.

Schindler, Robert M., and Morris B. Holbrook. 2003. Nostalgia for early experience as a determinant of consumer preferences. Psychology \& Marketing 20, no. 4: 275-302.

Schönle, Andreas. 2010. Modernity as a 'Destroyed Anthill': Tolstoy on history and aesthetics of ruins. In Ruins of Modernity, ed. Julia Hell and Andreas Schönle, 89-103. Durham, NC: Duke University Press.

Scotsman. (2011). Does the Riverside Transport Museum in Glasgow live up to its billing? . Retrieved Feb, 2012, from http://www.scotsman.com/news/arts/does the riverside transport_museum_in glasgow_1 ive up to its billing_1_1701376

Shankar, Ave., Richard Elliott, and Christina Goulding. 2001. Understanding consumption: Contributions from a narrative perspective. Journal of Marketing Management 17, nos. 3 4: 420-53.

Shaw, Christopher, and Malcolm Chase. 1989. The dimensions of nostalgia. In The imagined past: History and nostalgia, ed. Christopher Shaw and Malcolm Chase, 1-17. Manchester: Manchester University Press.

Shaw, Gareth, Adrian Bailey, and Allan Williams. 2011. Aspects of service-dominant logic and its implications for tourism management: Examples from the hotel industry. Tourism Management 32, no. 2: 207-14.

Simon, Nina. 2010. The participatory museum. San Francisco: Museum 20.

Stewart, Kathleen. 1988. Nostalgia - A Polemic. Cultural Anthropology 3, no. 3: 227-41.

Taheri, Babak, and Aliakbar Jafari. 2012. Museums as playful venues in the leisure society. In The contemporary tourist experience: Concepts and consequences, ed. Richard Sharpley and Philip Stone, New York: Routledge.

Venkatesh, Alladi, and Laura A. Meamber. 2008. The aesthetics of consumption and the consumer as an aesthetic subject. Consumption, Markets \& Culture 11. no. 1, 45-70.

White, Tabitha Ramsey, Anne-Marie Hede, and Ruth Rentschler. 2009. Lessons from arts experiences for service-dominant logic. Marketing Intelligence and Planning 27, no. 6: 775-88.

Woodside, Arch G., and Carol M. Megehee. 2010. Advancing consumer behaviour theory in tourism yia visual narrative art. International Journal of Tourism Research 12, no. 5: 41831.

\footnotetext{
'The concept of 'willing suspension of disbelief', first coined by Samuel Taylor Coleridge in his Biographia Literaria in 1817, denotes the status of suspending one's belief that a piece of artwork is not real. Suspension of one's disbelief is crucial to enjoying the aesthetics and fantasies of a piece of art.
} 